\title{
Referensi Penulisan Disertasi
}

\author{
Ismail Suardi Wekke \\ Sekolah Tinggi Agama Islam Negeri (STAIN) Sorong \\ Email: iswekke@gmail.com
}

\begin{abstract}
ABSTRAK
Artikel mengemukakan senarai laman web yang dapat digunakan sebagai pangkalan data penelusuran tesis dan (atau) disertasi. Terdapat lima laman web dengan masing-masing keunggulan yang berbeda. Termasuk mengemukakan kriteria disertasi yang baik.
\end{abstract}

Kata Kunci: Disertasi, Referensi,

\section{Pendahuluan}

Dalam menulis disertasi ada satu pertanyaan yang diajukan ke saya "apa sumber-sumber referensi yang dapat digunakan?”. Jika universitas melanggan pangkalan data jurnal, maka tidak ada masalah. Namun, bagi mahasiswa di perguruan tinggi yang tidak melanggan pangkalan data jurnal, akan menjadi masalah tersendiri.

Pertanyaan kedua, ada repository kampus yang tidak terbuka secara bebas. Hanya meta data disertasi yang disediakan. Ketika memerlukan versi lengkap disertasi tersebut, tidak tersedia dan harus menghubungi perguruan tinggi untuk permohonan izin. Ini memerlukan waktu yang juga melibatkan proses administrasi di tingkat birokrasi tertentu.

\section{Sumber Pangkalan Data Disertasi}

Menjawab pertanyaan mahasiswa pasca sarjana tersebut, kami kemukakan identifikasi laman web yan dapat digunakan dalam proses penulisan disertasi. Berikut ini sumber-sumber pangkalan data yang dapat diakses secara terbuka. Berita baiknya, semuanya gratis. Walaupun gratis tetap bereputasi karena diterbitkan oleh lembaga yang kredibel. Bukan pula data yang diperoleh dari pangkalan data yang berbayar kemudian disebarkan secara gratis.

Pertama, ProQuest ${ }^{\circledR}$ Dissertations \& Theses, dengan alamat https://pqdtopen.proquest.com. Laman ini disiapkan ProQuest. Disertasi yang disiapkan setelah 1997. Disamping layanan daring, juga disiapkan versi cetak dengan membayar sejumlah biaya sesuai dengan yang disenaraikan dalam laman web setelah pencarian judul tertentu.

Tesis dan disertasi, terutama yang terbit di perguruan tinggi Amerika Serikat dan kanada tersedia secara lengkap. Bahkan bisa didapatkan dalam bentuk lengkap secara keseluruhan, mulai halaman pertama sampai halaman terakhir. 


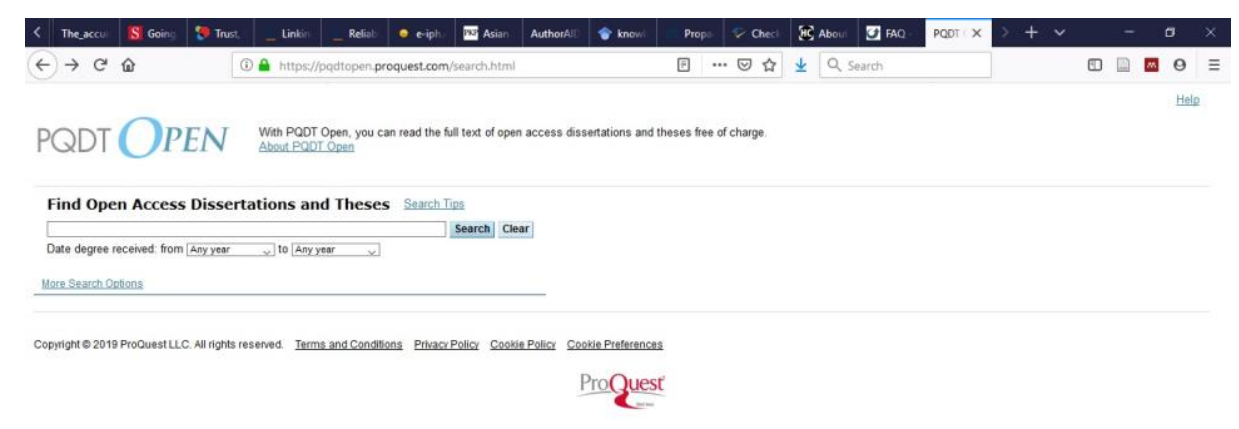

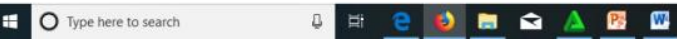

Gambar 1. ProQuest® Dissertations \& Theses

Kedua, Open Thesis melalui laman http://www.openthesis.org. Open thesis menjadi pangkalan data tesis. Berbanding dengan mengakses repository kampus dengan alamat berbedabeda. Sementara dengan Open Thesis cukup dengan mengakses satu alamat web.

Open Thesis menyediakan layanan bagi perguruan tinggi yang belum memiliki layanan repository. Bahkan walau sudah memiliki layanan itu, Open Thesis akan menjadi media diseminasi tesis yang dapat menjangkau lebih luas. Layanan Open Thesis sebagai media pencari tesis (dan disertasi) dapat menjadi platform untuk menyebarluaskan naskah tesis yang selama ini hanya berada di perpustakaan kampus dan diakses secara terbatas.

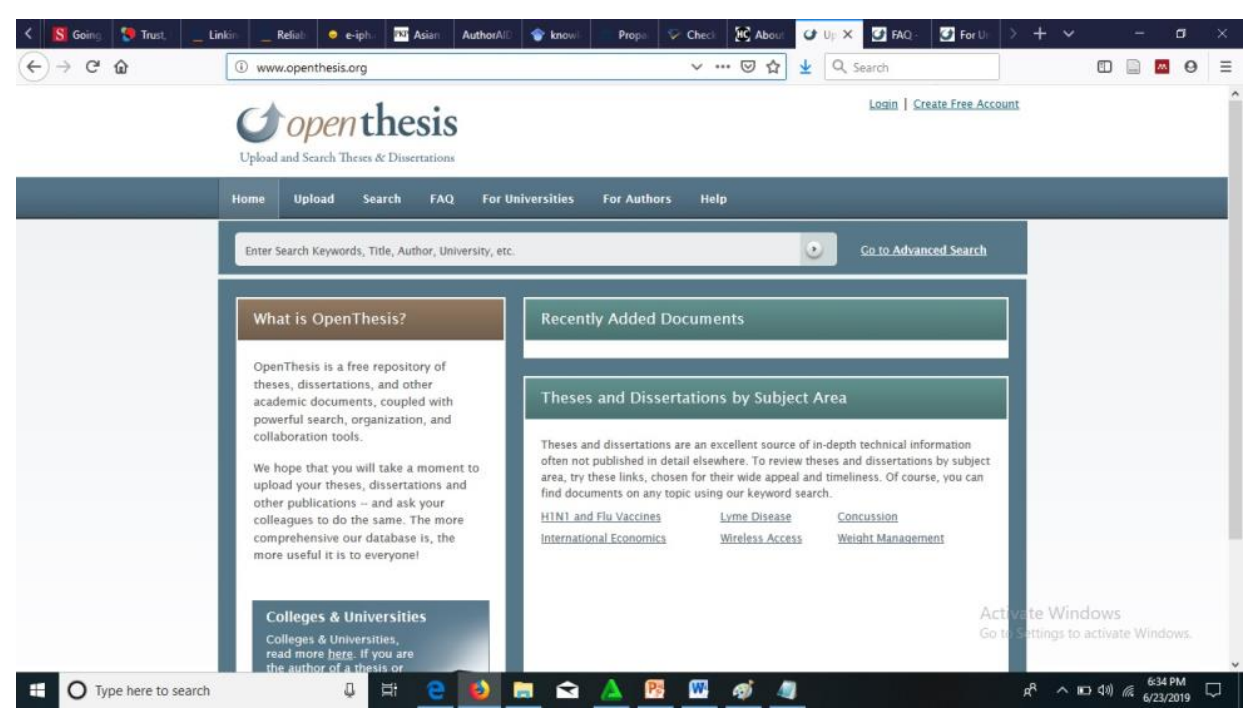

Gambar 2. Open Thesis

Ketiga, Open Access Theses and Dissertations dengan alamat https://oatd.org. terdapat 3.500.000 minimal tesis dan disertasi yang tersedia, dan terus bertambah setiap detik. Saya mengakses pada tanggal 23 Juni 2019. Setelah itu, bisajadi jumlahnya akan berbeda dengan data 
yang saya lihat. Data yang tersedia, juga disiapkan oleh Electronic Thesis and Disertation Consortia yang tersebar di 41 negara untuk masing-masing kawasan. Sementara laman web yang mencakup lintas negara terdapat enam laman web.

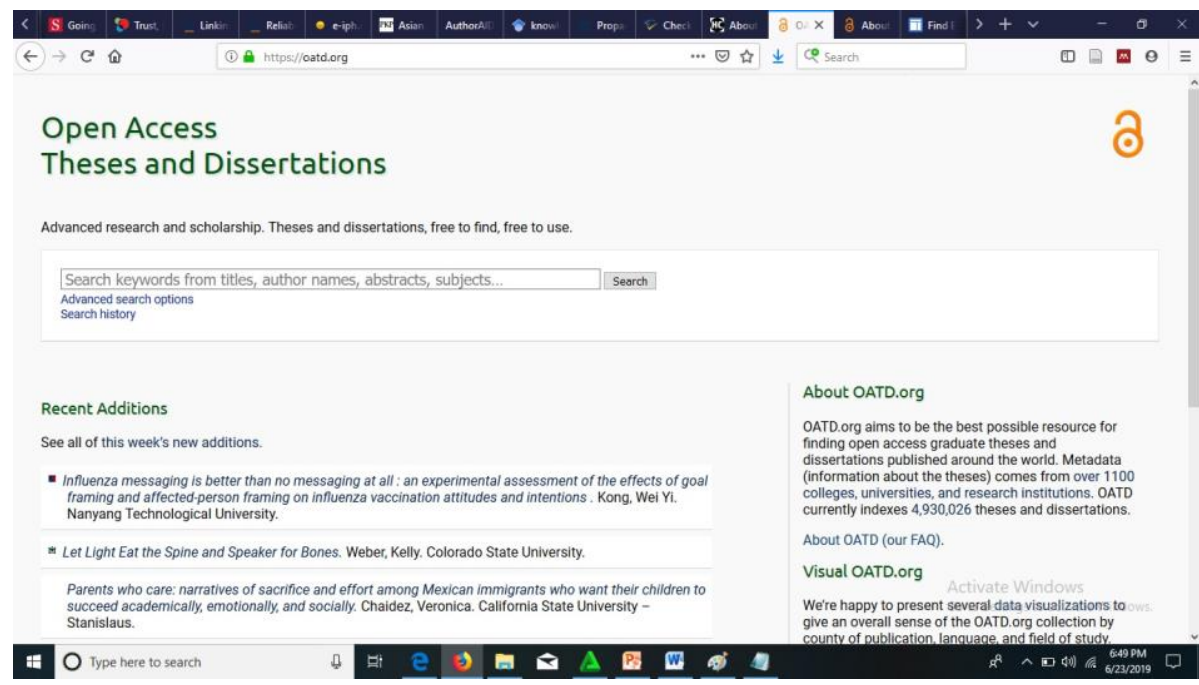

Gambar 3. Laman Web OATD

Untuk setiap negara, secara khusus dapat menggunakan alamat

http://www.ndltd.org/resources/find-etds.

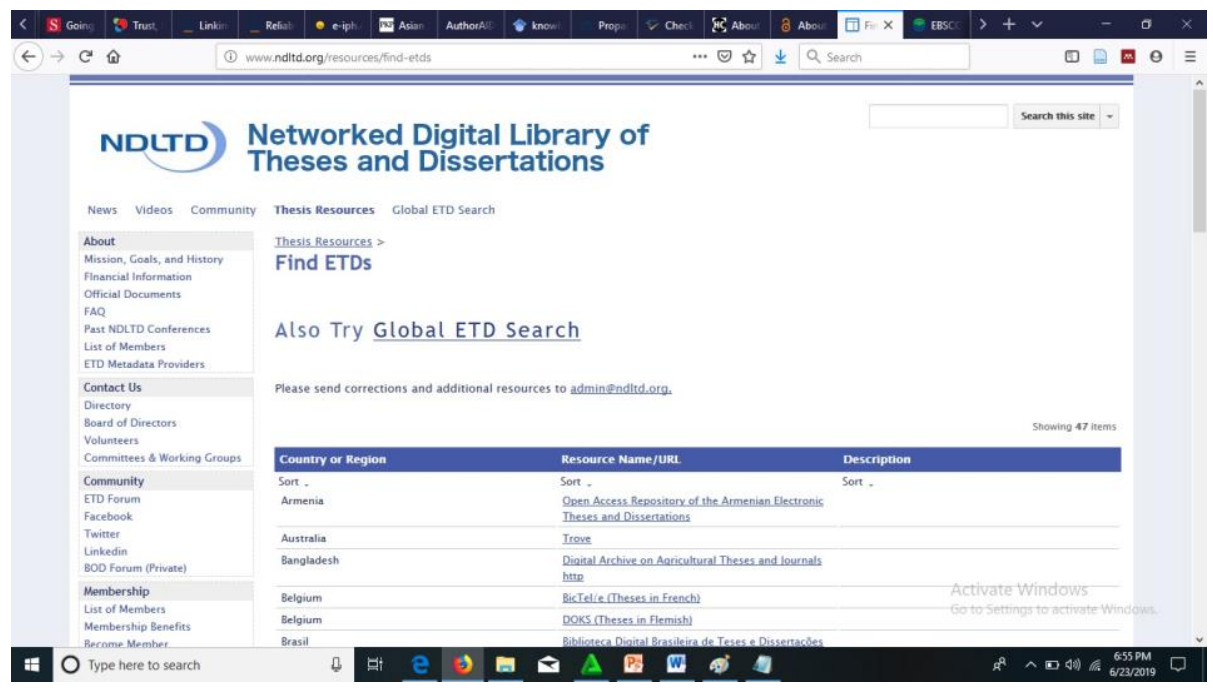

Gambar 4. Laman web yang menyediakan akses tesis ke 41 negara

Sementara untuk NDTLD dapat digunakan pada alamat http://search.ndltd.org. Networked Digital Library of Theses and Dissertations (NDLTD) menyediakan 5,770,236 tesis atau disertasi yang dapat ditelusuri. 


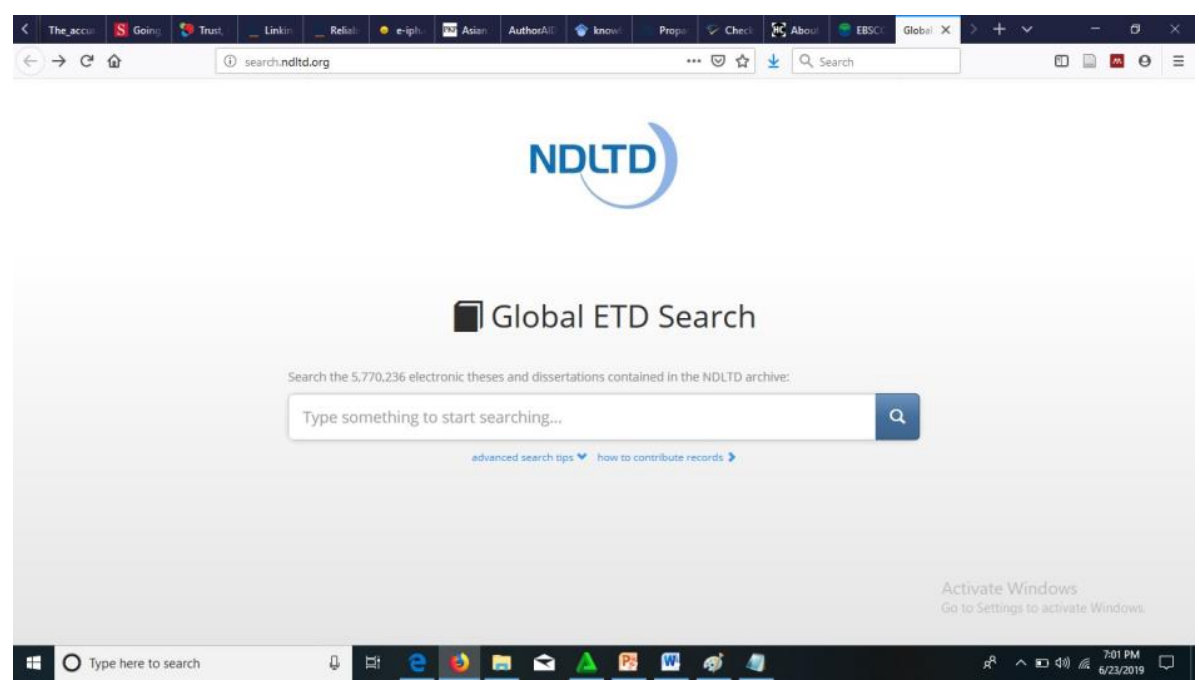

Gambar 5. Pencarian dengan NDLTD Global

Keempat, EBSCO Open yang beralamat di https://biblioboard.com/opendissertations. Prakarsa EBSCO dan BiblioLabs untuk menyediakan pangkalan data disertasi. didirikan pada tahun 2015 dan menyediakan data disertasi terutama perguruan tinggi Amerika sejak 1955 sampai sekarang.

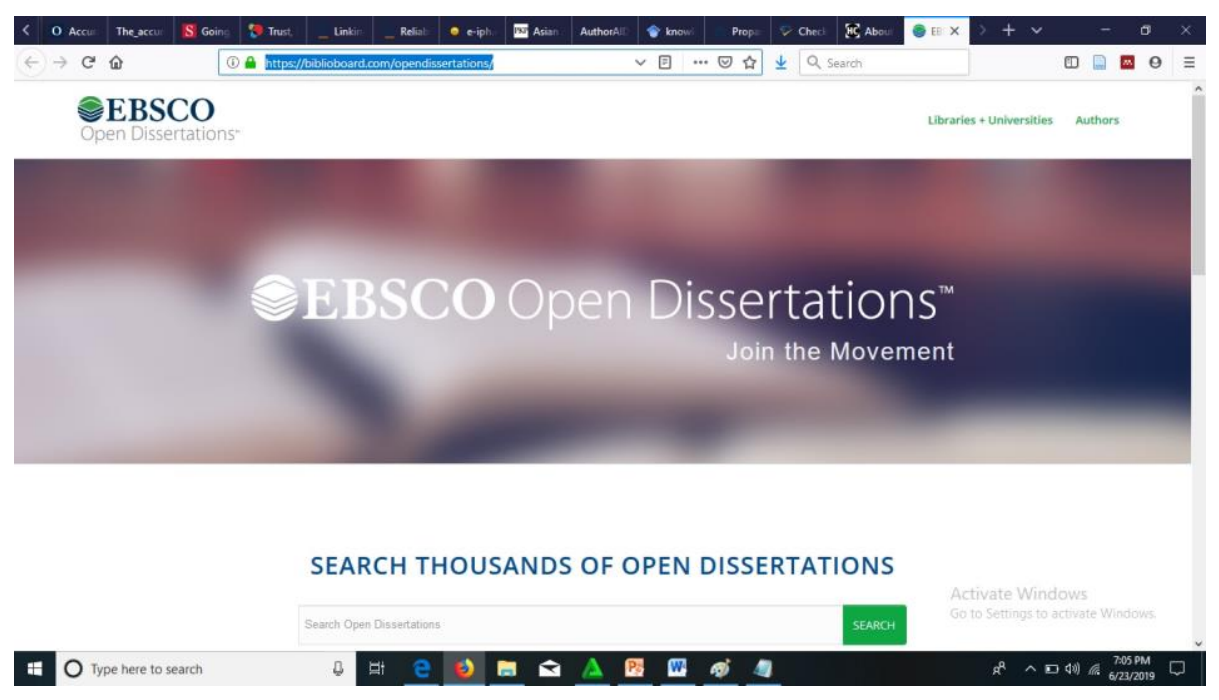

Gambar 6. ESBCO Open

Kelima, Malaysia Thesis Online beralamat http://myto.upm.edu.my/myTO/myto.html. Awalnya MyTho merupakan prakarsa Kementerian Pengajian Tinggi Malaysia. Sekarang MyTho ditempatkan di Universiti Putra Malaysia. Setiap tesis (atau disertasi) yang diselesaikan di perguruan tinggi negeri Malaysia tersedia dalam laman ini. 


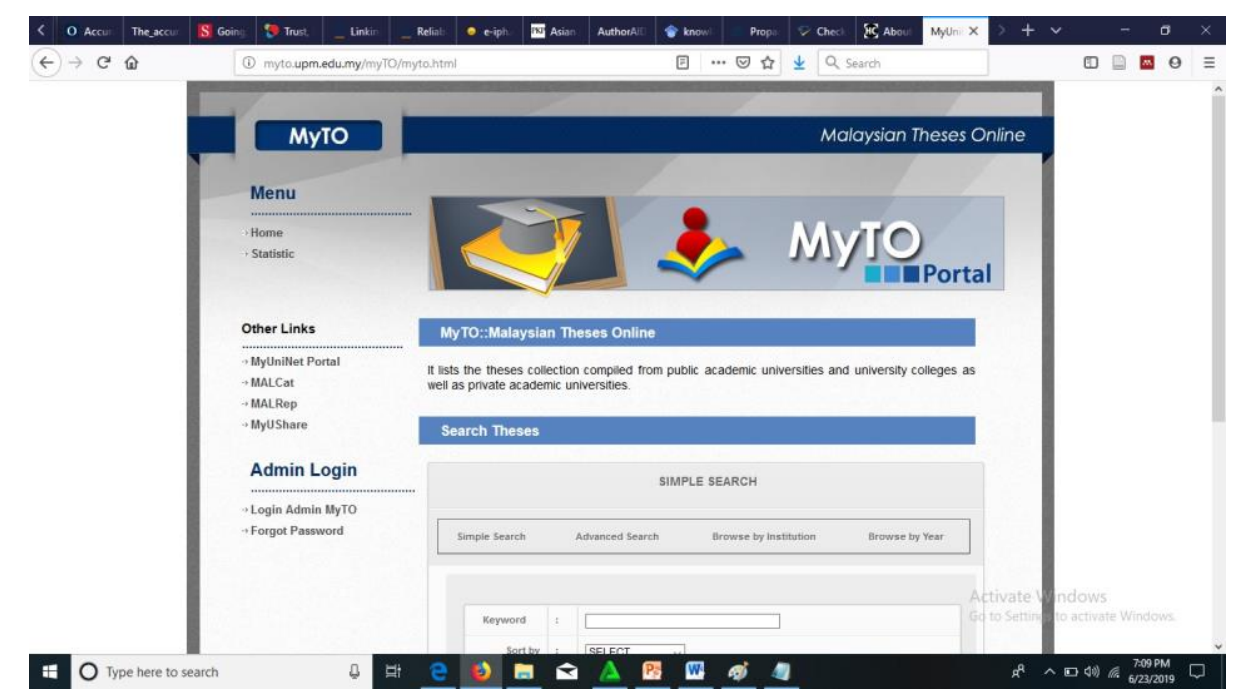

Gambar 7. Malaysia Thesis Online

Kelima laman ini dapat dijadikan sebagai mesin pencari dalam mengkaji literatur sebagai penerbitan terdahulu. Terutama terkait dengan disertasi yang sudah diselesaikan mahasiswa masing-masing di perguruan tinggi.

\section{Disertasi yang Baik}

Sebuah disertasi untuk sampai tahap penyelesaian memerlukan proses (Kavli \& Mikki, 2006). Jika itu diikuti, maka dengan proses yang berjalan akan memberikan peluang mahasiswa dalam menyelesaikan disertasi tepat waktu. Maka, setiap mahasiswa perlu mempersiapkan diri dengan proses yang dirancang sendiri sesuai dengan tahapan-tahapan yang ditentukan masingmasing perguruan tinggi. Sejak awal mahasiswa doktor perlu menelusuri topik kajian yang sudah ditulis dalam bidang ilmu yang ditekuni (Wekke, 2018). Kemudian dibangun dalam sebuah konteks keilmuan yang komprehensif (Brew \& Wekke, 2018).

Sebuah disertasi yang baik perlu dibedakan dengan tesis yang sudah ditulis sebelumnya pada tingkat magister. Jangan sampai disertasi yang sementara ditulis, sama saja dengan tesis yang sudah diselesaikan. Bahkan jangan sampai justru dama dengan skripsi yang merupakan hanya langkah awal dalam karir akademik (Wekke, 2017). Karakteristik disertasi perlu kajian lebih mendalam dan juga menjawab pertanyaan secara luas, tidak lagi hanya menjawab pertanyaan sebab akibat atas sebuah fenomena (Oliver, 2013). Disertasi merupakan pengembangan keilmuan sehingga perlu ditulis dengan proses melampaui kriteria dasar sekaligus memperhatikan kecenderungan diskursus keilmuan dalam masing-masing bidang ilmu pengetahuan (Maynard, Vaughn \& Sarteschi, 2012).

Penelurusan literatur menjadi kunci dalam menyusun kerangka sebuah disertasi. Jika mahasiswa sejak awal sudah menelusuri kepustakaan yang terkait, maka disertasi tersebut 
dibangun atas argumentasi yang komprehensif (Golding, Sharmini \& Lazarovitch, 2014). Ketepatan kepustakaan akan menjadi gambaran betapa disertasi tersebut ditulis dengan ketekunan dan ketelitian (Wekke, 2019). Tidak ditulis dengan baik saja, namun perlu menggambarkan sebuah kebaruan kajian (Rüger, 2016). Literatur perlu ditelurusi tidak hanya dalam satu atau perguruan tinggi terbatas, tetapi perlu dilakukan secara global dan lintas perguruan tinggi, lintas negara (Beile, Boote \& Killingsworth, 2003).

Terakhir, hubungan dengan pembimbing perlu dijaga dengan baik sehingga akan menghasilkan disertasi sesuai dengan standar minimal perguruan tinggi tempat kuliah (De Kleijn, Meijer, Pilot \& Brekelmans, 2014). Terkadang dalam penulisan disertasi terdapat hirarki antara dosen dan mahasiswa (Ray \& Marakas, 2007). Mahasiswa perlu menjaga relasi dengan dosen sehingga dapat terjaga selama proses penulisan disertasi. Bahkan setelah selesai dari program doktor sekalipun. Dosenpun kerap mengajukan pertanyaan dimana mahasiswa tidak rutin berkonsultasi dengan dosen pembimbing (Todd, Smith \& Bannister, 2006). Padahal kekerapan mahasiswa berkonsultasi menjadi bagian dalam proses penyelesaian disertasi. Walaupun demikian, penulisan disertasi lebih merupakan pekerjaan mahasiswa secara independen (Long \& Redding, 1991).

Satu lagi, menggunakan instrumen teknologi informasi menjadi alat dalam mengakselerasi penulisan disertasi (Nur, Sabara \& Wekke, 2018). Setidaknya, mahasiswa perlu berlatih dalam penguasaan alat yang dapat membantu penulisan disertasi. Begitu juga dengan kejujuran akademik yang perlu ditegakkan (Ardinansyah, Tenrisau, Aslim \& Wekke, 2018). Jika selama menulis disertasi justru berkubang dengan kecurangan, maka salah satu akibat yang bisa saja terjadi adalah pencabutan ijazah dan gelar yang sudah diselesaikan. Sejatinya, perguruan tinggi justru menjadi bagian dari usaha pencapaian kemahiran keilmuan yang tidak meninggalkan prinsip-prinsip ketuhanan (Sabri, Ikhsan \& Wekke, 2018). Dengan penggunaan teknologi justru memudahkan sekaligus menjadi godaan. Untuk itu, penggunaan teknologi tersebut perlu dibarengi dengan sikap ilmiah bahwa integritas akademik menjadi bagian yang tidak terpisahkan dalam proses penulisan disertasi.

\section{Penutup}

Artikel ini secara khusus menjawab pertanyaan sumber-sumber kepustakaan yang dapat digunakan dalam jaringan dalam rangka menelusuri disertasi. Termasuk menguraikan kriteria disertasi yang baik. Penggunaan sumber laman web akan membantu mahasiswa untuk menempatkan kajian disertasi dalam konteks keilmuan global. Dengan menggunakannya, akan mudah, cepat, dan paling penting tidak berbayar. 


\section{Daftar Pustaka}

Ardinansyah, A., Tenrisau, D., Aslim, F., \& Wekke, I. S. (2018). Ketidakjujuran Akademik Dalam Pendidikan Tinggi.

Beile, P., Boote, D., \& Killingsworth, E. (2003). Characteristics of education doctoral dissertation references: An inter-institutional analysis of review of literature citations.

Brew, A., \& Wekke, I. S. (2018). Hakikat Karya Ilmiah (The Nature of Research). Deepublish.

De Kleijn, R. A., Meijer, P. C., Pilot, A., \& Brekelmans, M. (2014). The relation between feedback perceptions and the supervisor-student relationship in master's thesis projects. Teaching in Higher Education, 19(4), 336-349.

Golding, C., Sharmini, S., \& Lazarovitch, A. (2014). What examiners do: What thesis students should know. Assessment \& Evaluation in Higher Education, 39(5), 563-576.

Kavli, S. M., \& Mikki, S. (2006). Enabling the student to write a good thesis: Combining information retrieval with the writing process.

Long, H. B., \& Redding, T. R. (1991). Self-Directed Learning Dissertation Abstracts 1966-1991. Oklahoma Research Center for Continuing Professional and Higher Education, McCarter Hall, University of Oklahoma, Norman, OK 73037.

Maynard, B. R., Vaughn, M. G., \& Sarteschi, C. M. (2012). The empirical status of social work dissertation research: Characteristics, trends and implications for the field. British Journal of Social Work, 44(2), 267-289.

Nur, T., Sabara, H. Z., \& Wekke, I. S. (2018). Teknik Menulis Karya Ilmiah: Dengan 8 Senjata Aplikasi Pendukung Produktivitas Riset. Deepublish.

Oliver, P. (2013). Writing your thesis. Sage.

Ray, S., \& Marakas, G. (2007). Selecting a doctoral dissertation supervisor: Analytical hierarchy approach to the multiple criteria problem. International Journal of Doctoral Studies, 2(1), 23-32.

Rüger, S. (2016). How to write a good $\mathrm{PhD}$ thesis and survive the viva. Knowledge media institute. Kents Hill: The Open University.

Sabri, M., Ikhsan, M., \& Wekke, I. S. (2018). Pengalaman Paramadina sebagai Rumah Pengetahuan Berbasis Nilai-nilai Ketuhanan, Tradisi Hikmah, dan Ilmu Pengetahuan. TEOSOFI: Jurnal Tasawuf dan Pemikiran Islam, 8(2), 373-405.

Todd, M. J., Smith, K., \& Bannister, P. (2006). Supervising a social science undergraduate dissertation: staff experiences and perceptions. Teaching in higher education, 11(2), 161173.

Wekke, I. S. (2017, November 7). Penyempurnaan Penulisan Skripsi. https://doi.org/10.31227/osf.io/qjxr5.

Wekke, I. S. (2018, May 30). Memulai Penelitian Dengan Menganalisis Topik Keilmuan. https://doi.org/10.31227/osf.io/yfrqz.

Wekke, I. S. (2019, June 12). Penelusuran Literatur Dalam Penulisan Artikel. https://doi.org/10.31227/osf.io/24tq6. 